\title{
A crack softening damage model for ceramic impact and its application within a hydrocode
}

\author{
Paul J. Hazell and Michael J. Iremonger \\ Cranfield University, Royal Military College of Science, Shrivenham, Swindon, SN6 8LA, UK
}

A physically based crack softening damage model has been developed and used in a non-linear transient dynamic computer code (AUTODYN-2D). It is assumed that there is a finite number of orientated pre-existing flaws within the ceramic target. The mode I and mode II stress intensity factors are calculated in compression and tension and the strain energy release rate is then estimated and compared to a critical dynamic strain energy release rate. At initiation, a tension crack propagates at a velocity dependent on the mode I stress intensity factor and failure occurs in a computational cell when two neighbouring microcracks coalesce. The model has been used to simulate two different plate impact experiments of alumina on alumina with encouraging results. The model has also been used to analyse the impact of a steel sphere on alumina and shows strong correlation between experimental and predicted results. 


\section{INTRODUCTION}

Under dynamic compressive loading, brittle materials generally deform inelastically. The inelastic response of the these brittle materials is usually attributed to the nucleation, growth and coalescence of microcracks. Early work [1] has shown that failure of polycrystalline alumina is controlled by microplasticity, i.e. twinning and possibly slip, which nucleate grain boundary cracks. The nucleation, growth and coalescence of these cracks causes extensive stiffness loss and strength degradation within the material [2].

Various models have been suggested for modelling the response of ceramics under dynamic loading. Ravichandran and Subhash [3] and Deng and Nemat-Nasser [4] used a sliding crack model [5] as a basis for modelling the failure of brittle materials under dynamic compressive loading. Addesio and Johnson [6] presented a microphysical model to describe the complex behaviour of ceramics under dynamic loading. Both crack opening due to tension and crack sliding due to compression were modelled. Rajendran [7] has successfully modelled the inelastic response of alumina using a "calibrated” approach where the physical parameters were matched with low velocity plate impact results. All of these authors have presented adequate verification of their approaches to modelling the impact of brittle materials.

AUTODYN [8] is a finite difference, non-linear explicit hydrocode which is capable of modelling a wide variety of dynamic situations. It includes a cumulative damage material model that degrades the material strength and stiffness as a function of 'damage'. This damage parameter is related to effective plastic strain in the material. 
Such a model does not relate closely to the physical crack softening mechanisms described above. Through the modification and implementation of a coded usersubroutine, a user can create models which simulate failure of a material loaded dynamically.

There is, therefore, a requirement for detailed crack softening models to be developed and implemented in hydrocodes such as AUTODYN. It is the authors' intention to present and discuss a physically based crack softening model which can be implemented within a hydrocode. Using the laws of fracture mechanics, equations are presented which are implemented within the coded user-subroutine in AUTODYN and validated under three different dynamic situations.

\section{CRACK SOFTENING DAMAGE MODEL}

\section{A. Dynamic failure in compression}

Most brittle solids contain inhomogeneities such as small holes, cracks or phases which have different moduli or strengths from those of the matrix. When a brittle material is subjected to a large confining stress, any of these inhomogeneities can act as nuclei for new cracks. These microcracks eventually coalesce to cause axial splitting.

For a straight slanted flaw that is loaded under biaxial compression, where $\sigma_{1}>\sigma_{2}$, tensile cracks nucleate from the tips of the flaw and grow in the direction of maximum compression $[9,10]$ as shown in Figure 1a: 
FIG. 1.

The tension cracks (or 'winglets') are assumed to grow so as to maximise the mode I stress intensity factor $\mathrm{K}_{\mathrm{I}}$. The growing 'winglets' are approximated by straight cracks because the sigmoidal cracks grow to several times the initial flaw length (Figure 1b) $[3,11]$. Under compression, the failure depends on the relative magnitude of the principal stresses, and for the case above, it is assumed that $\sigma_{1}$ is the largest principal stress. The kinked tension cracks are approximated by a single large crack of length 2 I which grows in the direction of maximum compression (Figure 1c). The analogy can also be applied to a crack emanating from a circular pore [12].

For an inclined crack (Figure 1c) subjected by compressive stresses $\sigma_{1}$ and $\sigma_{2}$, the crack is subjected to a co-linear opening load $T$. We can calculate $T$ by taking the contribution by the driving shear stresses on the inclined crack thus:

$$
T=2 a \tau_{\theta}
$$

Resolving the compressive stresses $\sigma_{1}$ and $\sigma_{2}$ and taking into account the resistive frictional stress $\tau_{F}$, we can calculate the driving shear stress $\tau_{\theta}$ of a sliding crack.

$$
\tau_{\theta}=\frac{1}{2}\left(\sigma_{1}-\sigma_{2}\right) \sin 2 \theta-\tau_{F}
$$

in which 


$$
\tau_{F}=\frac{1}{2} \eta\left[\left(\sigma_{1}+\sigma_{2}\right)+\left(\sigma_{1}-\sigma_{2}\right) \cos 2 \theta\right]
$$

This frictional shear stress $\left(\tau_{\mathrm{F}}\right)$, resists the shear load acting on the crack faces which provide the driving force for tensile crack propagation. $\eta$ is the coefficient of friction which is assumed to be uniform across the face of the crack.

The mode I and mode II stress intensity factors $\mathrm{K}_{\mathrm{I}}$ and $\mathrm{K}_{\mathrm{II}}$ at the tip of each of the tension cracks shown in Figure 1 and under biaxial compressive loading are given by

$$
K_{I}^{A}=\frac{T \cos \theta}{\sqrt{\pi}} \text { and } K_{I I}^{A}=\frac{T \sin \theta}{\sqrt{\pi}}
$$

where $T \cos \theta$ and $T \sin \theta$ are the crack opening and sliding loads respectively.

These results give good estimates of the stress intensity when I is large but it becomes unstable when the length I becomes vanishingly small. To overcome errors in the calculation of $K_{I}$ and $K_{I I}$ when the length of the tension cracks are extremely small we have added a constant $\left(I^{*}\right)$ to produce an 'effective' crack length $\left(I+I^{*}\right)$ which is dependant on the initial flaw size [11]. $I^{*}$ has been estimated [13] to be $0.27 \mathrm{a}$.

Moreover, the far field confining stress $\sigma_{2}$ contributes to the mode I stress intensity factor acting on the wing cracks to close the crack when $\sigma_{2}$ is compressive thus: 


$$
K_{I}^{B}=-\sigma_{2} \sqrt{\pi}
$$

Summing the contributions of A and B to the mode I stress intensity we finally have

$$
K_{I}=\frac{T \cos \theta}{\sqrt{\left[\pi\left(I+I^{*}\right)\right]}}-\sigma_{2} \sqrt{(\pi d)} \text { and } K_{I I}=\frac{-T \sin \theta}{\sqrt{\left[\pi\left(I+I^{*}\right)\right]}}
$$

In this instance, the compressive stresses are assumed to be positive.

\section{B. Dynamic failure in tension}

A large amount of failure observed in a brittle material subjected by a dynamic load is tensile. Hoop stresses induced by the radial movement of the material due to penetration is sufficient to nucleate tensile flaws which eventually coalesce and cause failure. Moreover, tensile spall planes are generated by tensile waves reflected off free surfaces which are able to interact with inhomogeneities and nucleate flaws.

When a tensile pulse passes a microcrack within a brittle material the mode I and mode II stress intensities depend on the time of duration and the speed of the pulse.

FIG. 2.

Assuming that the tensile pulse arrives uniformly at the crack tip, the stress intensity factors can be described [14] by 


$$
K_{I}(t)=C_{I} \sigma_{\theta} \sqrt{2 \pi c_{d} t} \text { and } K_{I I}(t)=C_{I I} \tau_{\theta} \sqrt{2 \pi c_{d} t}
$$

where $\sigma_{\theta}$ and $\tau_{\theta}$ are the resolved normal and shear stresses acting on the microcrack, $c_{d}$ and $c_{s}$ are the dilational and shear wave velocities and $t$ is time. $\mathrm{C}_{\mathrm{I}}$ and $\mathrm{C}_{\mathrm{II}}$ are material constants:

$$
C_{I}=\frac{\sqrt{2(1-v)}}{\pi(1-v)} \text { and } C_{I I}=\frac{2}{\pi} \frac{\sqrt{2 c_{s}}}{(1-v) c_{d}}
$$

where $v$ is the Poisson's ratio of the material.

\section{Crack Distribution}

It is assumed that there is a uniformly distributed number of microcracks of even length distributed through the target material. For simplicity, it is assumed that there is one orientated microcrack per cell, evenly distributed as shown in Figure 3. However, it is simple to apply a random Weibull Distribution function to the crack position and to vary the length in a random fashion. It is assumed that residual stresses within the material are minimal.

FIG. 3.

Although the orientations of microflaws are generally random, failure may occur from cracks which nucleate from microflaws of some suitable angle. The angle which is 
chosen here is as suggested by Nemat-Nasser and Deng [15], namely $\theta=\pi / 5$. The length of the initial microflaw is taken to be the average size of a microflaw within the material.

\section{Crack initiation}

In the conventional static Linear Elastic Fracture Mechanics, the condition for the onset of crack growth is often expressed as

$$
K=K_{c}
$$

where $\mathrm{K}_{\mathrm{c}}$ is called the critical stress intensity factor (often called the static fracture toughness). In elastodynamic fracture there are two counterparts to the equation. First for the onset of growth of a rapidly loaded stationary crack we have

$$
K(t, 0)=K_{d}(\dot{\sigma})
$$

where $K_{d}$ is the dynamic initiation toughness which may also depend on the temperature.

Second, for dynamically propagating cracks it has been suggested that

$$
K(t, i)=K_{D}(i)
$$


where $K_{D}$ is the dynamic propagation toughness for propagating cracks and $i$ represents the rate of crack growth.

It has been shown experimentally [16] that

$$
\frac{K_{d}}{K_{c}}=\alpha
$$

where $\alpha$ is a constant. At initiation, $\alpha$ varies between $1.25-1.40$ for ceramics [17]. According to the criterion given above, a propagating crack will be arrested when the stress intensity factor becomes smaller than or equal to a critical value.

This can be expressed as

$$
K \leq K_{D}(0) \equiv K_{I a}^{d y n}
$$

where $K_{I a}^{d y n}$ denotes the dynamic crack arrest toughness.

Shockey, Kalthoff and Erlick [18] reported a substantial reduction of the crack initiation toughness in brittle epoxy due to dynamic loading. The estimate for the fracture toughness under dynamic loading conditions imposed was about $\mathrm{K}_{\mathrm{Id}}=$ $0.72 \mathrm{MPa} \sqrt{m}$ compared to the slow moving fracture toughness of $\mathrm{K}_{\mathrm{Ic}}=1.1 \mathrm{MPa} \sqrt{m}$. For ceramics however, the opposite seems to occur. Yang and Kobayashi [19] noted 
an increase in initiation toughness under dynamic loading conditions. Unlike metals and polymers, they observed that the dynamic crack arrest toughness did not exist i.e. once crack growth was initiated, stable crack growth was observed even when the stress intensity was lowered.

The virtual energy release rate for a stationary microcrack affected by a static and transient load (plane strain) is given [14] by

$$
G=\frac{1-v^{2}}{E}\left(K_{I}^{2}+K_{I I}^{2}\right)
$$

where $E$ represents the Young's modulus of the material.

To calculate the virtual energy release rate of the crack, for both compression and tension, the respective mode I and mode II stress intensity factors are substituted into (14). This then is checked against a critical virtual energy release rate $G_{c}$.

Because the mode I and mode II stress intensities in compression are calculated from Linear Elastic Fracture Mechanics, we must consider the effect of loading the specimen dynamically. We do this by introducing the relationship:

$$
\frac{G_{d y n}}{G}=h
$$


where $G_{d y n}$ is the dynamic virtual energy release rate, $G$ is the static virtual energy release rate calculated from Equation 14 and $h$ is a constant to be calculated from experimental data. Both the dynamic and static critical energy release rate (plane strain) for tensile crack initiation can be calculated using the relationship:

$$
G_{c}=\frac{\left(1-v^{2}\right)}{E} K_{I c}
$$

Table 1 shows the comparison of the static and the dynamic fracture toughness and their corresponding critical energy release rates for two grades of alumina, Coors AD995 and AD998. The average value of $h$ from the three references for the two grades of alumina is 1.69. No data is currently available for Sintox-FA.

The modified value of the virtual energy release rate is compared with the critical energy release rate for crack initiation:

$$
G_{d y n}=G_{c}
$$

Table I.

In tension however, the mode I and mode II stress intensity factors are calculated from the laws of elastodynamic fracture mechanics and a simple initiation law can therefore be used:

$$
G=G_{c}
$$




\section{E. Crack propagation velocity}

Once a crack has initiated, it will propagate at a velocity dependent on the applied stress intensity [20]. Under compression, the crack will propagate in a stable manner; under tension the crack will propagate catastrophically at a velocity ( $i$ ) fast approaching the Rayleigh wave speed $\left(\mathrm{C}_{\mathrm{R}}\right)$ of the material. Failure in compression and in tension is described by

$$
i=c_{R}\left(1-\frac{K_{d}}{K_{I}}\right)
$$

Although $K_{d}$ is a function of the rate of applied stress for most materials little evidence exists to support this for ceramics $[17,19,21]$. In this instance, $K_{d}$ is assumed constant and can be calculated by substituting a value of the critical stress intensity factor for ceramic (4MPa $\sqrt{\mathrm{m}}$ ) and the values of $\alpha$ in Table 1 into Equation (12).

\section{AUTODYN MODEL AND VERIFICATION}

AUTODYN is a finite difference hydrocode with the option of using Lagrangian, Eulerian, Arbitrary Lagrange Euler (ALE) and Shell processors. For this paper, the Lagrangian processor was used. AUTODYN can be linked with a user supplied subroutine to modify the existing program and to implement a new equation of state, strength or damage model. A linear equation of state is used along with a MohrCoulomb strength model to represent the undamaged ceramic. 


\section{A. Code implementation}

For each cycle, the mode I and mode II stress intensity factors (Equations 6 and 7) are calculated for a single pre-existing flaw, the size of which was taken to be the average grain size of the material (2a in Figure 1 and Table 2). From these, the strain energy release rate is calculated (Equation 14) and compared with the critical value (Equations 17 and 18). If this critical value is exceeded, the crack will grow at a calculated velocity (Equation 19). The cracks will grow when under compression or tension. It is assumed that the cell is unable to carry load when the crack has propagated through the entire cell and coalesces with a neighbouring microcrack. Each crack is able to propagate past the cell boundaries by simply adding the length exceeding the cell dimension to the neighbouring crack. A scalar damage parameter varying between 0 and 1 is defined in accordance with crack growth, where 0 represents no crack growth and 1 represents complete coalescence and failure of the Lagrangian cell. This damage parameter is used to linearly degrade the elastic moduli and the yield strength depending on the pressure within the cell [8]. Alternative mechanisms of strength and moduli degradation due to microcracking are available $[22,23]$.

This new crack softening model was used in three simulations and the results compared with those from experimental investigation. The material data used is summarised in Table 2. 
Two completely different plate impact experiments were compared with the microcrack model to validate the material response. Firstly, Song, Bless, Brar, Simha and Jang [24] impacted a high purity alumina plate at a velocity of $735 \mathrm{~m} / \mathrm{s}$ against an alumina target backed by steel (Model Run A1). Secondly, Dandekar and Bartowski [25] again impacted alumina on alumina, but backed by polymethylmethacrylate (PMMA) (Model Run A2). The impact velocity in this case was $83 \mathrm{~m} / \mathrm{s}$. In both experiments the axial stress was measured at the target - backing interface. The results of the plate impact experiments and the microcrack model predictions are compared in Figures 4 and 5:

FIG. 4.

FIG. 5.

\section{B. Simulation of sphere impact}

The model was used to investigate the impact of steel spheres against thick blocks of alumina (Model Run A3). Experiments were conducted in which spheres were mounted in plastic sabots and fired from a 7.62mm rifle barrel using a standard 7.62mm cartridge case filled with Hercules Blue Dot propellant. Three EN31 6.35mm steel spheres were fired at high velocity against free standing $100 \times 100 \times 50 \mathrm{~mm}$ alumina (Sintox FA) targets and the results were compared to AUTODYN predictions using the crack softening damage model. The depth of penetration and the size of the 
comminuted material (the "Mescall zone" [26]) next to the projectile nose were examined and plotted in Figures 6 and 7:

FIG. 6.

FIG. 7.

The results show strong correlation between the experiment and the model. It is quite clear that the strength of the damaged material plays an important role in the penetration of the projectile. Over estimation of the strength of the comminuted material will reduce the depth of penetration, underestimation will increase penetration.

\section{CONCLUSIONS}

A new crack softening damage model based on the laws of dynamic fracture mechanics has been presented. Comparison with two different flyer plate experiments have shown that the model closely follows experimental data. The model has been used to analyse sphere impact experiments at varying velocities and has proven effective in quantifying depth of penetration and damage.

\section{ACKNOWLEDGEMENTS}


The authors would like to thank R.N.L. Smith for his helpful advice in the preparation of this paper. This work was done under the financial support of the Engineering and Physical Sciences Research Council and British Aerospace Defence, Royal Ordnance Division. 
1. J. Lankford, J. Mater. Sci., 12, 791 (1977).

2. D. C Larsen, J. W. Adams, S. A. Bortz and R. Ruh, Proceedings of the International Symposium on the Fracture Mechanics of Ceramics, in Fracture Mechanics of Ceramics, Plenum Press, New York, 571 (1983).

3. G. Ravichandran and G. Subhash, Int. J. Solids and Structures, 32, 2627 (1995).

4. H. Deng and S. Nemat-Nasser, Mech. Mater., 14, 83 (1992).

5. W. F. Brace and E. G. Bombolakis, J. Geophys. Res., 68, 3709 (1963).

6. F. L. Addessio and J. N. Johnson, J. Appl. Phys., 67, No. 7, (1990).

7. A. M. Rajendran, High Pressure Science and Technology - 1993, Part 2, AIP Press, New York, 725 (1994).

8. AUTODYN ${ }^{\mathrm{TM}}$ Theory Manual. Century Dynamics Inc. (1995).

9. H. Horri and S. Nemat-Nasser, J. Geophys. Res., 90, 3105 (1985).

10. G. Venkins, M. F. Ashby and P. W. R. Beaumont, Acta metall. mater., 39, 2583 (1991).

11. M. F. Ashby and S. D. Hallam, Acta Metall. Mater., 34, 497 (1986).

12. M. F. Ashby and C. G. Sammis, PAGEOPH, 133, No. 3, 489 (1990).

13. H. Horri and S. Nemat-Nasser, Phil. Trans. R. Soc. Lond., 319, 227 (1986).

14. L. B. Freund, Dynamic Fracture Mechanics, Cambridge University Press, (1990).

15. S. Nemat-Nasser and H. Deng, Acta Metall. Mater., 42, 1013 (1994). 
16. K. Kishida, T. Yokoyama and M. Nakano, Proc. 3rd Conf. Mech. Prop. High Rates of Strain, Inst. Phys. Conf. Ser., 70, 221 (1984).

17. J. Duffy, T. Nakamura, Y. Yeshurun and S. Suresh, Proc. 4th Conf. Mech. Prop. High Rates of Strain, Inst. Phys. Conf. Ser. 102, 335 (1989).

18. D. A. Shockey, J. F. Kalthoff and D. C. Erlick, Int. J. of Fract., 22, 217 (1983).

19. K. Yang and A. S. Kobayashi, J. Am. Ceram. Soc. 73, 2309 (1990).

20. J. W. Dally, W. L. Fourney and G. R. Irwin, Int. J. Fract., 27, 159 (1985).

21. S. Suresh, T. Nakamura, Y. Yeshurun, K, H, Yang and J. Duffy, J. Am. Ceram. Soc., 73, 2457 (1990).

22. B. Budianskey and R. O’Connell, Int. J. Solids Structures, 12, 81 (1976).

23. Y. Huang, A. Chandra, Z. Q. Jiang, X. Wei and K. X. Hu, Int. J. Solids Structures, 33, 1575 (1996).

24. H. Song, S. J. Bless, N. S Brar, C. H. Simha and S. D. Jang, High Pressure Science and Technology - 1993, Part 2, AIP Press, New York, 737 (1994).

25. D. P. Dandekar and P. Bartowski, High Pressure Science and Technology - 1993, Part 2, AIP Press, New York, 733 (1994).

26. D. R. Curran, L. Seamen, T. Cooper and D. A. Shockey, Int. J. Impact Engng., 13, 53 (1993). 
FIG. 1. The approximation of an angled crack within a unit cell subjected to a confining stress $\left(\sigma_{1}>\sigma_{2}\right)$.

FIG. 2. A crack being submitted to a uniform stress wave of magnitude $\sigma$.

FIG. 3. Crack softening model: initial distribution of flaws in cells of height h and width w.

Table I. Comparison of dynamic and static fracture toughness values for alumina and their corresponding critical energy release rates.

Table II. Material data required by the model.

FIG. 4. Comparison of computed stress history with plate impact experimental data for an impact velocity of 735m/s (Song, Bless, Brar, Simha and Jang [24]).

FIG. 5. Comparison of computed stress history with plate impact experimental data for an impact velocity of 83m/s (Dandekar and Bartowski [25]).

FIG. 6. Comparison between the experimental and numerical depth of penetration into alumina by a steel sphere (linear regression through the experimental data).

FIG. 7. Comparison between the experimental and numerical comminuted depth of alumina impacted by a steel sphere (linear regression through the experimental data). 


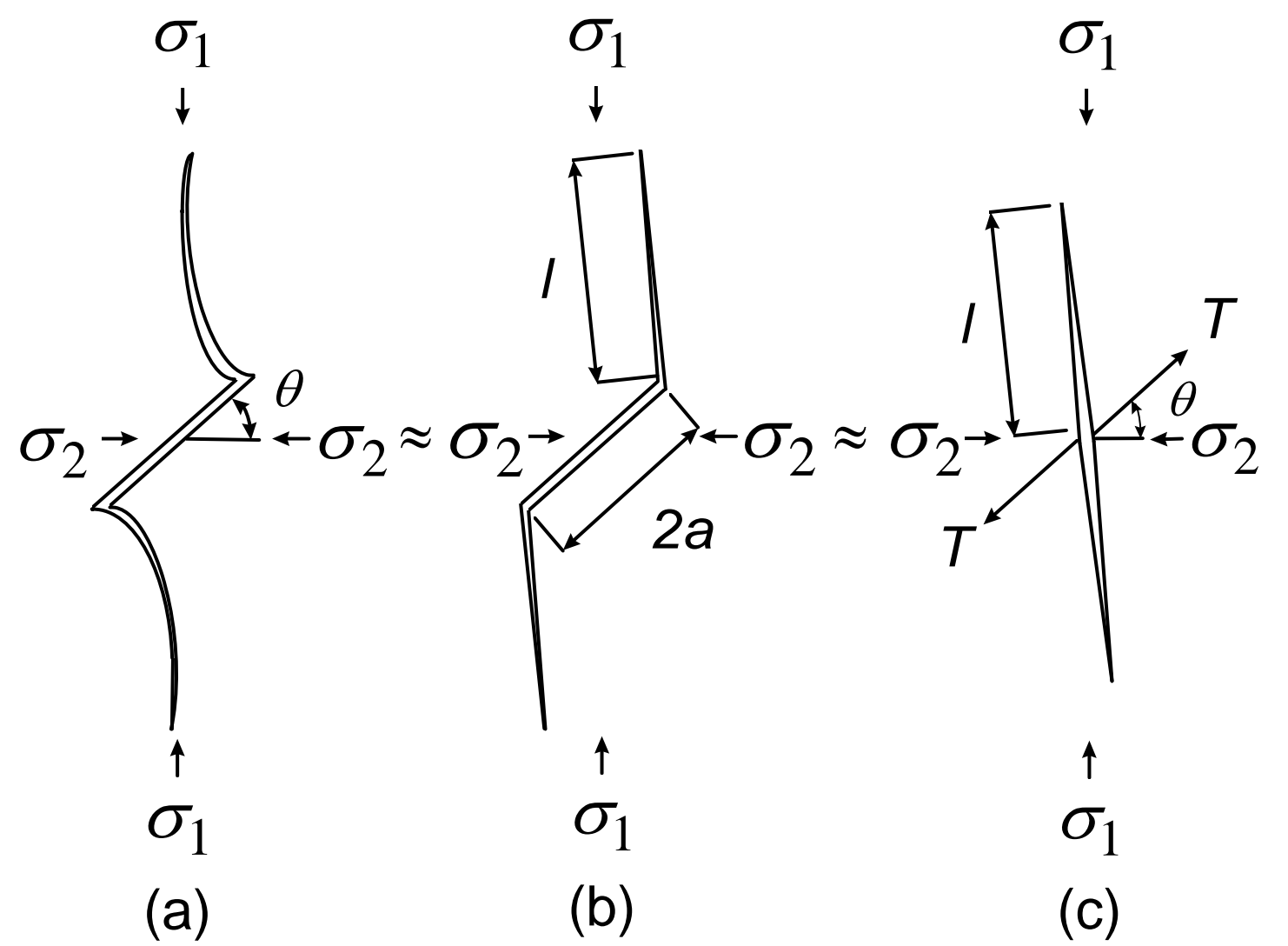

FIG. 1. (Hazell and Iremonger) 


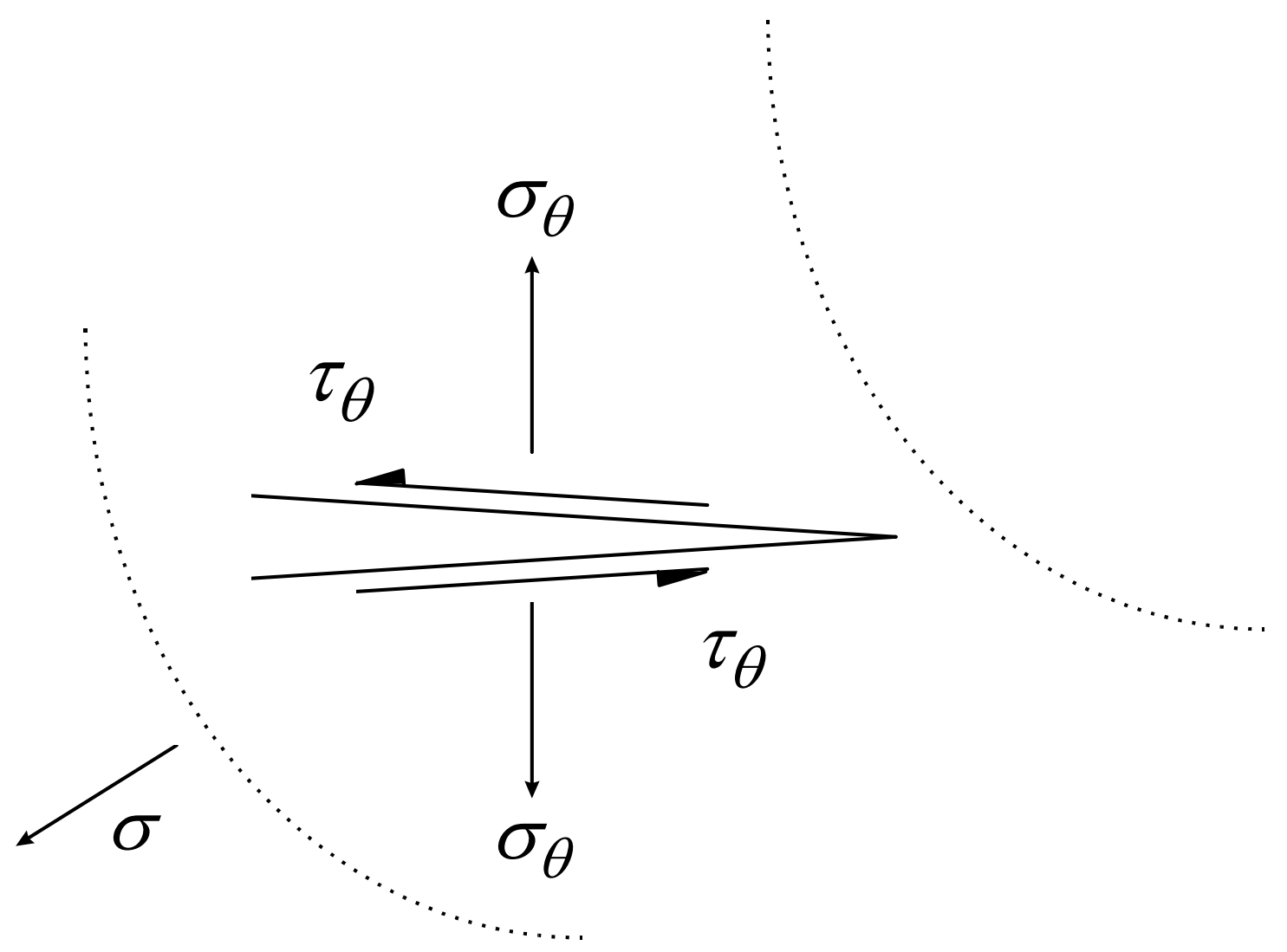

FIG. 2. (Hazell and Iremonger) 


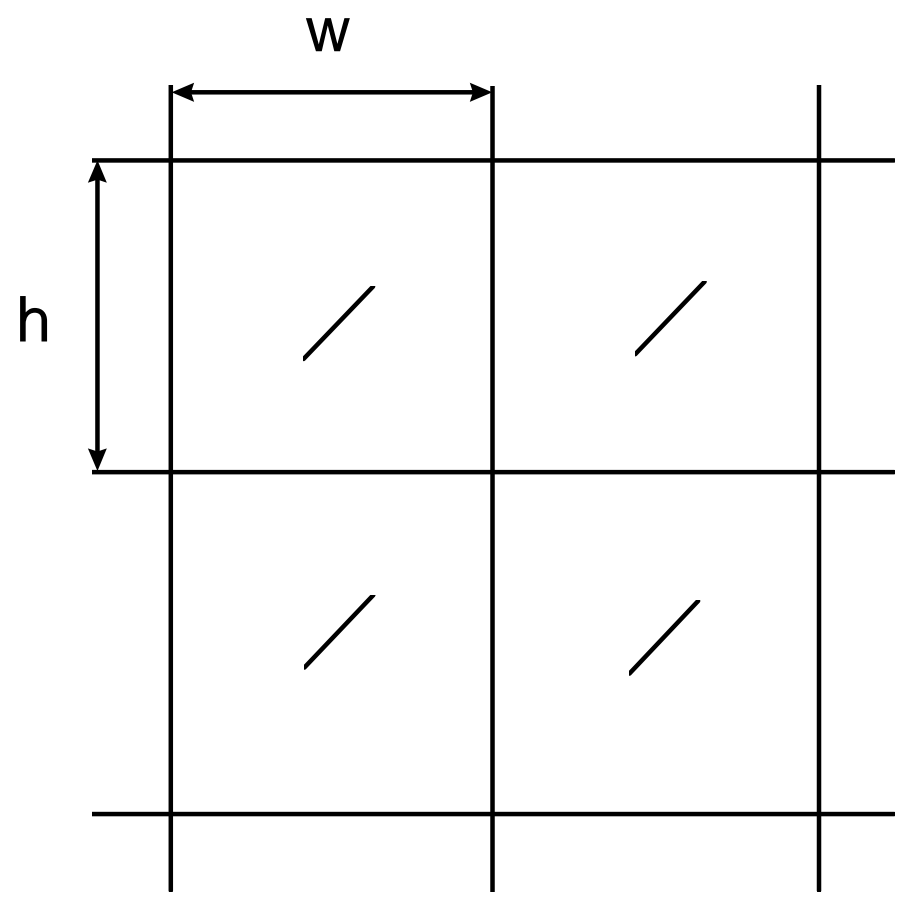

FIG. 3. (Hazell and Iremonger) 
TABLE I. (Hazell and Iremonger)

\begin{tabular}{cccccccc}
\hline Ref. & $\begin{array}{c}\mathrm{K}_{\mathrm{ic}} \\
(\mathrm{MPa} \sqrt{\mathrm{m}})\end{array}$ & $\begin{array}{c}\mathrm{K}_{\mathrm{id}} \\
(\mathrm{MPa} \sqrt{\mathrm{m}})\end{array}$ & $\begin{array}{c}\alpha \\
\left(\mathrm{K}_{\mathrm{id}} / \mathrm{K}_{\mathrm{ic}}\right)\end{array}$ & $\begin{array}{c}\mathrm{G}_{\mathrm{c}} \\
\left(\mathrm{J} / \mathrm{m}^{2}\right)\end{array}$ & $\begin{array}{c}\mathrm{G}_{\mathrm{d}} \\
\left(\mathrm{J} / \mathrm{m}^{2}\right)\end{array}$ & $\begin{array}{c}\mathrm{h} \\
\left(\mathrm{G}_{\mathrm{d}} / \mathrm{G}_{\mathrm{c}}\right)\end{array}$ & $\begin{array}{c}\text { Alumina } \\
(\text { Coors })\end{array}$ \\
\hline$[17]$ & 2.7 & 3.5 & 1.30 & 20.0 & 33.7 & 1.69 & AD998 \\
{$[19]$} & 4.3 & 5.7 & 1.33 & 46.0 & 80.7 & 1.75 & AD995 \\
{$[21]$} & 2.9 & 3.7 & 1.28 & 23.1 & 37.7 & 1.63 & AD998 \\
\hline
\end{tabular}

TABLE II. (Hazell and Iremonger)

\begin{tabular}{|c|c|c|c|c|c|c|c|c|}
\hline $\begin{array}{l}\text { Model } \\
\text { Run }\end{array}$ & $\begin{array}{c}\text { Alumina } \\
\text { Content (\%) }\end{array}$ & $\begin{array}{l}\text { Density } \\
\text { (g/cc) }\end{array}$ & $\begin{array}{c}E \\
(\mathrm{GPa})\end{array}$ & $v$ & $\eta$ & $\begin{array}{c}2 \mathrm{a} \\
(\mu \mathrm{m})\end{array}$ & $\begin{array}{c}\mathrm{C}_{\mathrm{d}} \\
(\mathrm{m} / \mathrm{s})\end{array}$ & $\begin{array}{c}\mathrm{C}_{\mathrm{s}} \\
(\mathrm{m} / \mathrm{s})\end{array}$ \\
\hline A1 & 98.0 & 3.990 & 371 & 0.25 & 0.72 & 10 & 10800 & 6300 \\
\hline $\mathrm{A} 2$ & 99.5 & 3.880 & 382 & 0.23 & 0.72 & 6 & 10560 & 6250 \\
\hline A3 & 95.0 & 3.694 & 308 & 0.24 & 0.72 & 5 & 9890 & 5803 \\
\hline
\end{tabular}




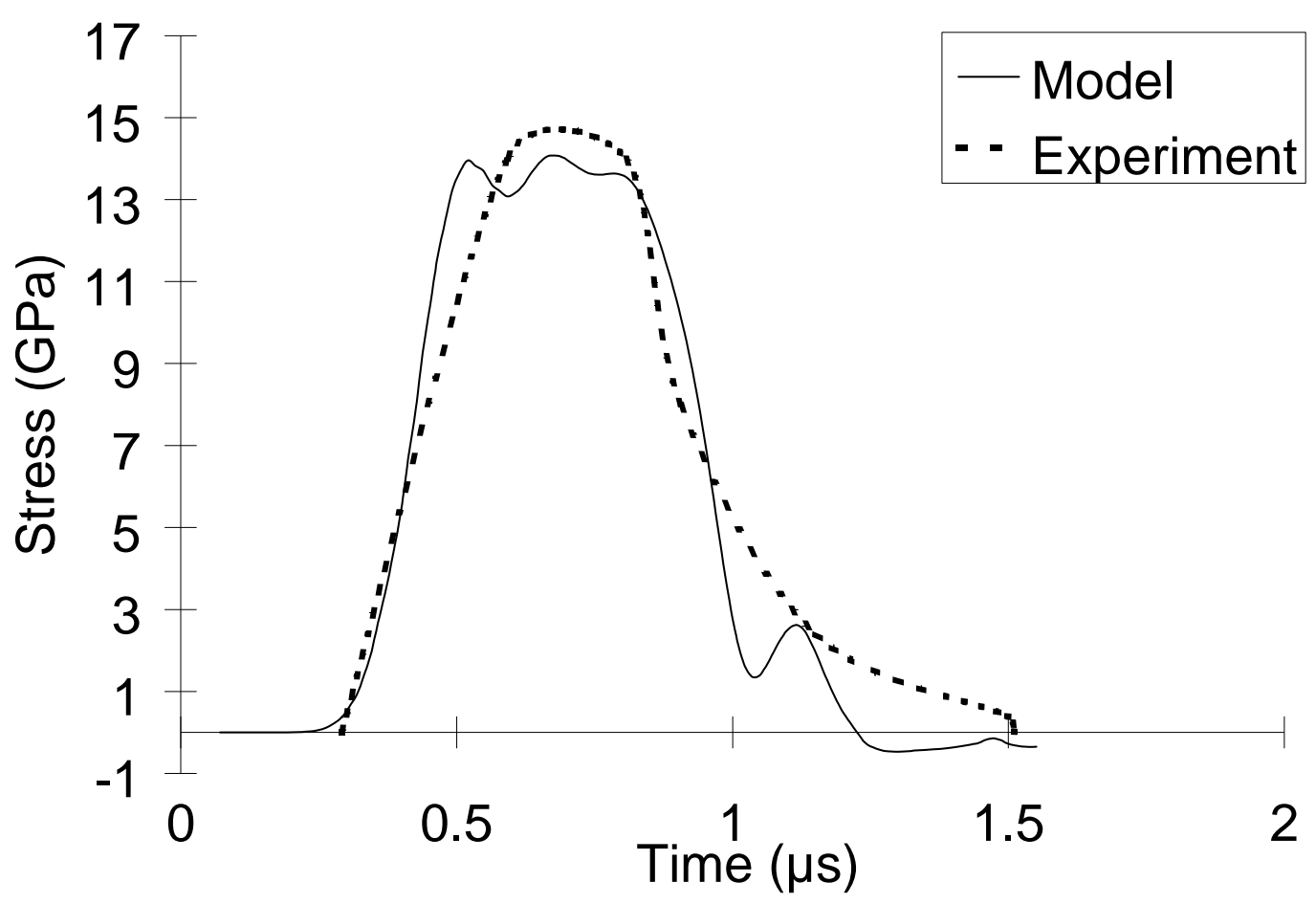

FIG. 4. (Hazell and Iremonger) 


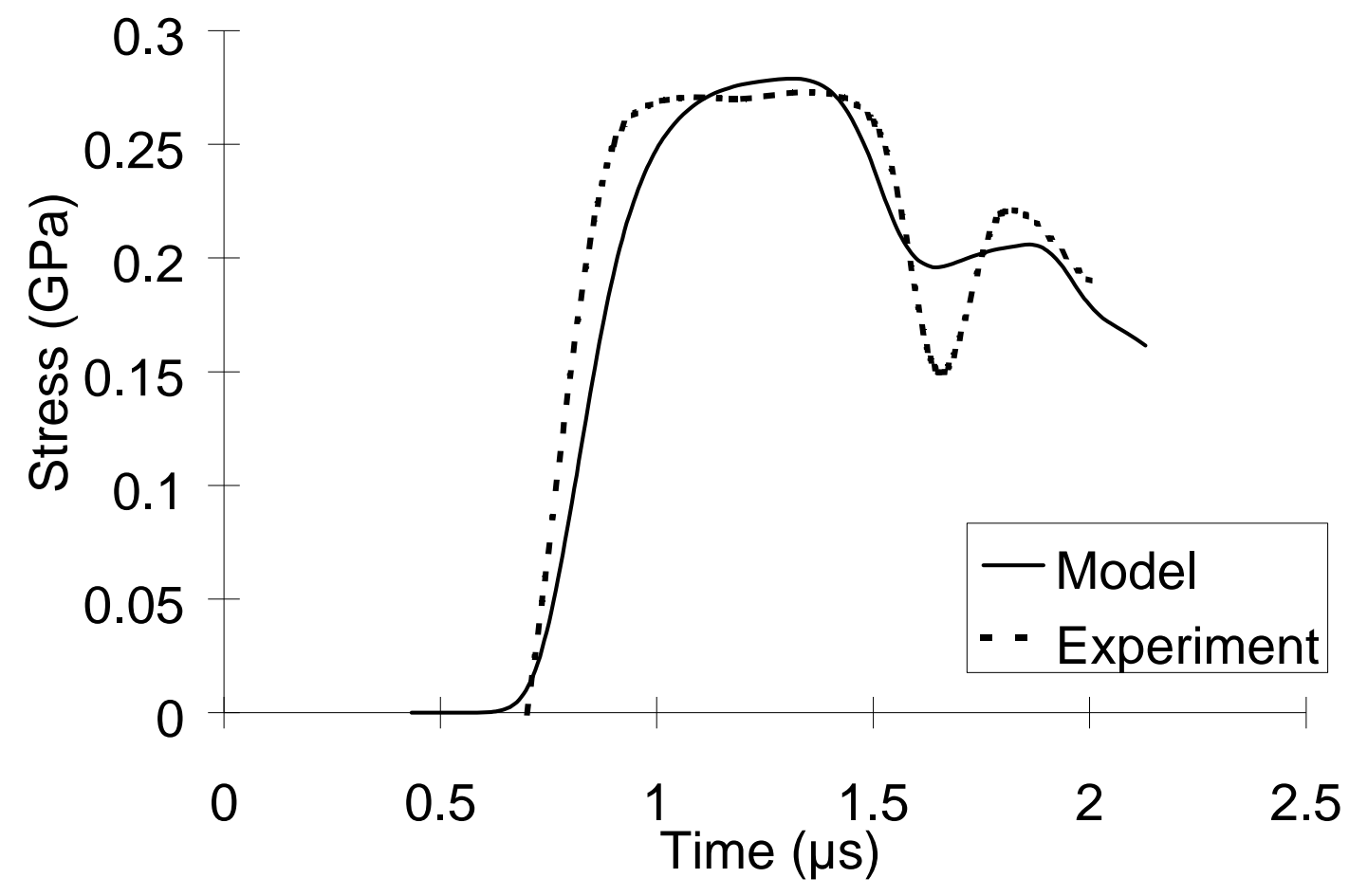

FIG. 5. (Hazell and Iremonger) 


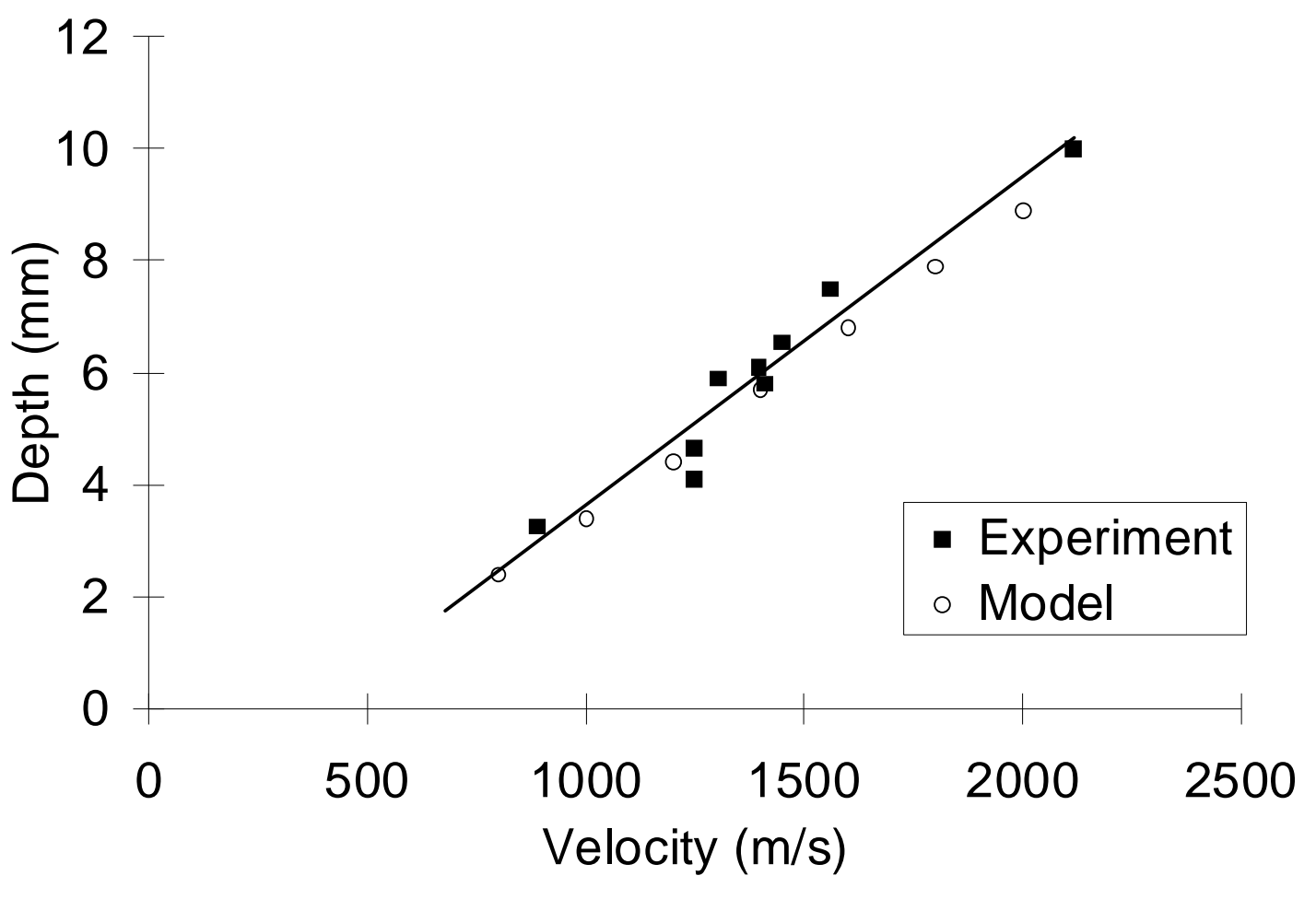

FIG. 6. (Hazell and Iremonger) 


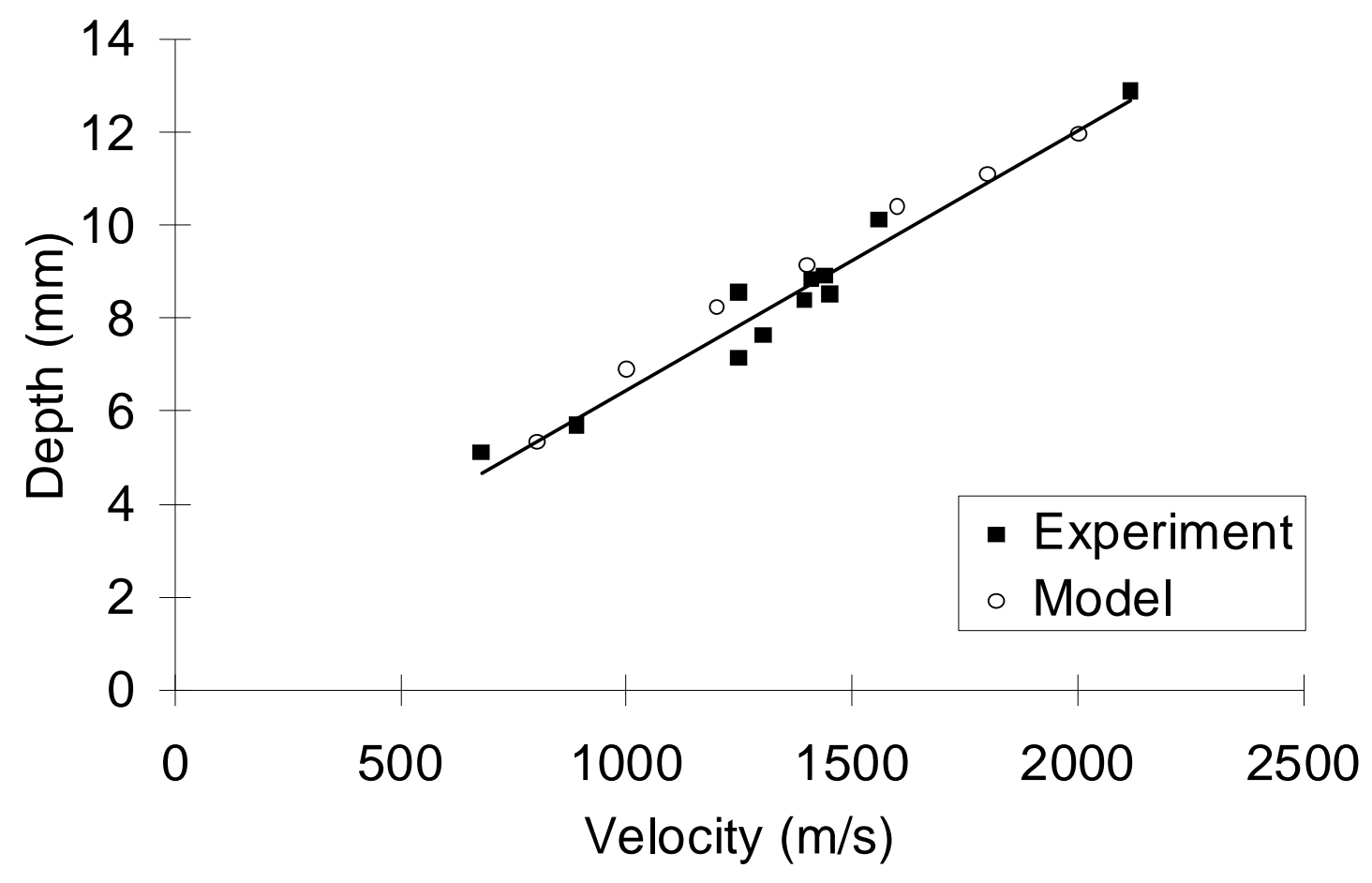

FIG. 7. (Hazell and Iremonger) 